\title{
6 \\ Ownership of ideas and things \\ a case study of the politics of the Kuk prehistoric site
}

\section{John D Muke}

They have used me and made so much money out of me and now, you come here to protect the things that will make others become famous in future. You also come to sell my ideas and things. What have you given back to me? (Ongka, personal communication 1994). ${ }^{1}$

Jack Golson came and we worked together in the ditches. He paid us for our labour but he took the knowledge to Australia. He did not leave it here with us. You want us to look after these things of the ancestors, but they are of value to the future. Now the Kawelka are short of land and have divided the blocks among themselves. It is hard for me to try and stop them from destroying the prehistoric sites. You know when they have already made their gardens, they will ask you for money if you want to excavate on their land (Ru, personal communication 1997). ${ }^{2}$

In Papua New Guinea today, natural resources are seen as property to be exploited. Cultural resources are increasingly equated with natural resources and intellectual property rights provide an avenue for them, too, to be exploited. Whereas natural resources are an embodiment of nature, cultural resources are products of human society. Papua New Guinea's unique cultural heritage includes social practices and material traces that remind present generations of their origins and the world of their ancestors. It also includes an archaeological record that goes beyond the threshold of human memory, extending over 50,000 years of human occupation.

Understandings about the ownership of ideas and things among the people of Papua New Guinea affect the way this cultural heritage is treated today. Changing opportunities to market culture and changing perceptions of 
outsiders have created new expectations among the owners and custodians of cultural artifacts and knowledge. These expectations must influence approaches to the preservation and promotion of Papua New Guinean cultural heritage, but they should also inform debates about intellectual property. Intellectual property rights that serve to commodify culture even further may not be in the long-term interests of the owners of cultural knowledge, or those of the country as a whole.

This chapter discusses people's attitudes towards the ownership of ideas and things. The word ownership is chosen in preference to intellectual property rights. For some people, the word intelligence is associated with success in the formal education system. Intellectual property rights can therefore be seen as rights only accruing to a few selfish members of the educated élite. This poses a question worth considering - what are the intellectual property rights of the residents of Morata settlement in Port Moresby?

The quotations at the beginning of this chapter were recorded during conversations with two prominent local leaders from Kuk historical site in Western Highlands Province. This chapter considers issues of the ownership of ideas and things from the perspective of the makers of these two statements. At the heart of the issues are the relationships between the leaders of Kuk and the academics who came to study the site. In discussing these relationships, I wish to acknowledge that I have benefited from continued interaction with the leaders of this area-through constant dialogue - and with the academics who have studied it - through reading their writings. I am particularly indebted to the writings of Andrew Strathern (1985), Marilyn Strathern (1996) and Jack Golson $(1977,1982)$.

The chapter is written from a number of overlapping perspectives-as a member of a neighbouring community, as a researcher trained in an analytical framework and as an intellectual seeking to explore the concept of intellectual property rights. It begins with an outline of the background to the debate about the Kuk site, and then considers in turn the issues raised by the statements of the two informants.

\section{Background to the Kuk debate}

In the late 1960s, the Department of Primary Industry purchased 700 acres of swamp in the Kuk basin from its owners, the Kawelka tribe, to establish a tea plantation, which later became an agricultural research station. Early in its history, Jim Allen, recently appointed as a lecturer in prehistory in the Department of Anthropology and Sociology at the new University of Papua 
New Guinea, visited the station and saw the sort of evidence for ancient swamp drainage and cultivation which Jack Golson of the Australian National University had previously reported for the Warrawau tea plantation (Allen 1970; Golson et al. 1967).

The Kuk site has since acquired international significance as a result of the work of Golson, who, in collaboration with several other scientists, has dedicated much of his scholarly life to the reconstruction of the gardening systems. Six major systems were revealed-9,000 BP, 6,000-5,500 BP, 4,000-2,500 BP, 2,000-1,200 BP, 400-250 BP and 250-100 BP. 3 Microscopic parts of plants growing in the swamp or carried into it by wind or water from outside gave information about forest, grassland, climate and human cultures. Wooden artifacts (wooden spades and digging sticks) recovered from permanently waterlogged conditions provided information about the kind of technology used in the management of wet and dry land cultivations (Golson 1977, 1982).

Kuk is now known throughout the world as one of the earliest centres of independent innovation of agriculture, regularly acknowledged in standard introductory textbooks (Fagan 1980:198, 1990:224-6; Renfrew and Bahn 1991:228). Part of the significance of the site lies in the tangible evidence it provides of a sense of identity and habitation that equal the history of human occupation anywhere in the world (Groube et al. 1986). These revelations not only provide an important piece of the jigsaw about human history-they also help to debunk the myths about small-scale tribal societies that are embedded in phrases like 'primitive' and 'stone age'.

\section{The death of scientific interest in Kuk}

One of the reasons why the Kuk site is so well known, and has provided so much evidence of significance, is that issues of a political nature did not impede nearly 20 years of scientific research. There was no conflict of interest between the local landowners and the efforts by academics and authorities to study and protect this ancient cultural resource. The site was located on a property belonging to the state. With a series of understanding station managers, it was protected from destruction by the fact that the eastern half of the station was not brought into immediate cultivation.

Towards the end of 1990 , it was decided to close the Kuk station. A number of reasons appear to have prompted this, including declining government revenue as a result of the Panguna copper mine closure, and concerns about the safety of staff. Staff of the provincial government of the 
Western Highlands attempted to negotiate with local landowners a way of mothballing the property until operations could start up again. It was proposed that provincial public servants should occupy the vacated houses, and part of the rent collected should go back to the villagers. A general agreement was reached among the landowners to open a passbook account to receive the rent. However, misuse of the account led to a dispute among the Kawelka, who in turn harassed the public servants. This led to the total abandonment of the station. The residential compound was subsequently occupied by the landowners themselves.

In November 1993, Golson and I, along with a team of archaeology students, went to Kuk to meet with the local landowners of the now abandoned station, taking with us officers from the Division of Culture and Tourism and the Division of Agriculture and Livestock (formerly the Division of Primary Industry) of the Western Highlands Provincial Government. The objective was to discuss plans for future land use and to seek ways of protecting and preserving parts of the Kuk archaeological records as national heritage (Strathern and Stewart 1998). Golson and I returned in June 1994 to see how things were developing on the ground at Kuk, and again in May 1997, after the continued inactivity of the Division of Agriculture and Livestock had led to the land being taken over by the traditional owners. I myself made annual trips to the site, during which a number of lengthy discussions were held about its cultural importance, not only to Papua New Guinea but to the history of humanity.

The statements from Ongka and $\mathrm{Ru}$ set out above emerged from these conversations. They address issues of the ownership of ideas and things. In the following parts of the chapter I analyse Ongka's statement in the context of reciprocity of knowledge and Ru's comments in relationship to the ownership of things.

\section{Ownership of knowledge}

Kawelka Ongka developed a long-term relationship with the archaeologists who came to work at the Kuk site, as he had done previously with social anthropologists, especially Andrew Strathern, who were independently engaged in studies of the Kawelka community. He appeared in four films and published his own autobiography, translated by Andrew Strathern at his behest (Ongka 1979). The products of this relationship - exchanges of ideas, information and materials-ensured both fame for the researchers and an increase in Ongka's own standing within his culture. Yet notwithstanding this, Onkga's comments question the role of anthropologists in the 
production of knowledge about Kuk and the benefits that should flow to him as an informant.

\section{Responses to foreign researchers in Papua New Guinea}

The discipline of anthropology has a long history of involvement in Papua New Guinea. Anthropology developed at a time when few parts of the world had been unaffected by European colonisation. Papua New Guinea's fame in the anthropological world during the first half of the twentieth century stemmed from perceptions that it was one of the last untouched frontiers for anthropologists.

The exposure of tribal groups in Papua New Guinea to research work has generated considerable criticism. Andrew Strathern (1985) has usefully summarised some of these criticisms and many of them are addressed in his writings. They include

- anthropological writing demeans the indigenous communities as primitive

- anthropology has been intimately linked to the colonial order

- knowledge gained through research is exploited in the form of books and articles

- the field has no practical value.

The proposition that anthropology is linked to the colonial order is lent some weight by historical circumstance. Anthropology has traditionally been an avenue for the West to express its views of other cultures. Non-literate and non-industrial 'primitive' cultures, organised on a small scale, were contrasted with the complexities of the modern industrial world. As such, early anthropology provided a scientific justification for colonial domination by European powers.

Strathern argues that although anthropology may have had Eurocentric roots, by 1950 its major contribution was to promote decolonisation. Anthropologists did not assist the colonial regimes directly, and colonials generally treated them as outsiders in the European network. Remarking on his own role, Strathern (1985:171) commented: 'I did not exactly feel, then, that I was at the very hub of the wheel of colonialism at this time'. Still the fact remains that he came into contact with the natives as a European first.

For if it is true that no production of knowledge in the human sciences can ever ignore or disclaim its author's involvement as a human subject in his own circumstances, then it must also be true that for a European or American studying the Orient [the Melpa] there can be no disclaiming the main circumstances of his actuality: that he comes up against the Orient [the Melpa] as a European or American first, as an individual second (Said 1991:11). 
Over the years, indigenous and foreign scholars have debated these issues. A number of indigenous academics and others have questioned the rationale, justification and benefits to be gained from researching tribal communities, including Morauta (1979) and Talyaga (1974). Concerns about exploitation feature prominently among them. On this issue too, Strathern (1985) offers an opposing viewpoint. He argues that it is usually educated Papua New Guineans who dislike the idea of PhDs (cast in this context as commodities) being manufactured from the raw material of knowledge about traditional societies. He labels this kind of rationality as 'zero sum thinking', and argues that 'a $\mathrm{PhD}$ should not simply be seen as an absolute gain to the person who obtains it', because 'a thesis can be written so as to be interesting to those who are its subjects' (Strathern 1985:174). The pontification by national élites is an unnecessary charge, he says, and urges them to team up with expatriate colleagues to concentrate on salvage anthropology, otherwise the knowledge might be lost forever.

However, the comments about intellectual property made by Ongka and $\mathrm{Ru}$ are not those of educated élites, but come from the people who, Strathern says, know the situation and base their comments on 'perceived reciprocity or the lack of it' (Strathern 1985:173). Strathern defends his research work on the basis that people living in Mt Hagen think it is a good thing I had written so many books and articles because these carried their own names outwards, and also brought many visitors back to them' (Strathern 1985:173). If this is so, why did Ongka say 'you come here to make money out of my ideas and things'?

\section{Reciprocity: the cultural context of knowledge}

Ongka's perspective is that his intellectual creativity represents an investment in the future, like a seed. If it is successful, and the tree that grows from his seed bears fruit, then those who have benefited from the fruit will be indebted to him as the source person. This corresponds to the Wahgi concept of reproductive kinship incorporating roots (uncles), base (mother) and transplants. In this context, transplants are always indebted to their source people for their own wellbeing. From Ongka's perspective, it was through him as a source person that others have attained fame, status and wealth (Muke 1992; O'Hanlon and Frankland 1986). Therefore researchers were indebted to him.

Marilyn Strathern (1996:23) puts it this way: 'Like wind-borne seeds success (texts) is measured by the numbers of sites at which it grows'. Ongka felt that he was an equal partner in the sowing of seeds-or, to use 
Marilyn Strathern's phrase, the 'dispersal of knowledge'-and he had high expectations of an obligation to receive at a later stage. In one sense therefore, the concept of originator that is familiar in an intellectual property context finds an unlikely parallel with a society based on exchange mechanisms. Yet, in the context of ongoing reciprocity, it can be difficult to distinguish who is the producer of the knowledge that is the useable product.

\section{Attitudes to researchers in the Wahgi}

When Ongka was a young boy, there were very few anthropological records relating to the Hageners of the Wahgi Valley, where the Kuk basin is located. Early descriptions of its society were made by missionaries and patrol officers entering the region after it was opened up to colonial exploration in the 1930 s. During the 1970 s, it was hardly possible to keep abreast of research findings relating to the Central Highlands of Papua New Guinea (Brown 1978:264). By the 1980 s, there were few peoples and areas that remained unstudied; several had been studied more than once. Researchers began to turn their attention elsewhere, perhaps in recognition that the Highlands, once a region of exciting anthropological prospect, was finally a bit 'overexposed' (Feil 1987:2).

Ongka was part of the generation in which too much anthropology was done. For this reason it is intriguing that he directed his questions about the use of knowledge not to those he had worked with, but to myself, a thirdwave anthropologist (or rather, a first-wave native studying himself). Perhaps Ongka was aware from the beginning that he was involved in the production of knowledge that had the potential to be created and transformed into something else. Marilyn Strathern (1996) says that potential becomes an asset, and establishing intellectual property is one way of securing control over the potential life of creative ideas with reference to both their production and their future.

In the Highlands, the politics of reciprocity govern expectations about social relations. The giving of a gift creates the potential to return something at a later stage, whether the value inherent in the gift is higher or lower than the previous gift which it reciprocates. If he knowingly accepted the way (he thinks) he was exploited, then Ongka probably did so because he felt himself to be in a situation in which the rules of perceived reciprocity applied.

The reason why knowledge is now perceived to have been stolen may lie in the way the inhabitants of the Wahgi perceive white men 
(Connolly and Anderson 1987). The Hageners perceived Europeans as 'manifestations of light-skinned sky beings... [who were] the ultimate source behind the power of social groups to reproduce themselves' (Strathern 1984:20). Despite Andrew Strathern's argument that his entry into the Wahgi Valley had nothing to do with the process of colonisation, but rather coincided with the process of decolonisation, it is nevertheless true that, as a European, he would have been credited with being part of the 'origin people' (in Melpa pulk-wamb), the true owners of exotic material items-steel, clothes, valua-bles, food and equipment. The class and ideological differences among the Europeans may not have been apparent to the Hageners. For them, white men all came from the same tribe. The Hagen ideas about perceived recip-rocity enabled Ongka to place Strathern in the position of a source person. $\mathrm{He}$ may have rationalised that through himself as the potential customer, recipient or 'path person', Western wealth would be channelled, reproduced, embedded and redistributed in the Kawelka sociopolitical settings.

An important factor about reciprocity is that it involves interpersonal relations between individuals who are expected to place themselves symmetrically; at birth they are equals and they engage in exchanges as equal partners. For the duration of this relationship, as they exchange information, ideas, food, material wealth and so forth, the role of 'originator-of-theconcept' shifts between a network of credit and debt relations. A credit is created when one gives gifts in the form of ideas, spiritual blessings, transferring of divine planting substances, daughters in marriage and so forth. The recipient must feel compelled to make a return at a later stage but not necessarily to the exact value-rather the aim is to cement the continuation of an existing social relationship. The original donor may feel that the exact value of the initial gift is not matched by the recipient but this really does not matter, so long as one gets something in return for previous debts. Some credit-debit relations are short-term; others, like the inheritance of divine substances, carry over several generations. A relationship between the scholar and the informant may have ended when the former completed the fieldwork, but the informant would still have an expectation about sharing in the products of the scholarship.

This may be one of the reasons why Ongka featured in four films and was the subject of several books, whereby the notion of stealing ideas and things became only secondary, but could be activated if positive relations turned into negative reciprocity. He may have expected that the scholars who worked with him would ensure he received returns from the products of 'useable knowledge'. 


\section{Relationships between researchers and subjects}

It is extremely difficult for researchers to maintain long-term relationships with their informants because of 'the demands of their career, family, and society' (Strathern 1985:173).

Outside the context of the fieldwork interaction, the relationship between the researcher and the subject changes. Taken from this perspective, the relationship can be usefully analysed using two of the three property ownership categories suggested by Marilyn Strathern (1996). I have recontextualised them as different levels of reciprocity: the originator of the products of collective life (cultural property rights) and the creator-producer of the products of useable knowledge (intellectual property rights).

The subject of research may have earnestly believed that he had found a new partner of equivalence who came from the source of the exotic items of wealth-pulk wamb (origin, roots or source people). However, what the subject did not know is that his new exchange partner had concealed his background, unconsciously or otherwise, and assumed a role of equivalence with the natives around him. Within his own culture, the researcher was born into an unequal position (lower or upper class and so on), and competes with others in a learning institution. His adventure into the Wahgi, for example, is an indication that he had successfully surpassed his own colleagues, and reached a level of success that entitled him to enjoy the fruits of his intellectual labour.

Behind this presumed reciprocity, the natives were unaware that these strangers felt free to use alien categories-- the first betrayal of the principle of equivalence- to record and observe their lives. The researchers would look beyond the proverbs, parabolic expressions, rhetorical devices, pointed anecdotes and so forth, but instead of finding individuals in personal relationships, would look for the underlying structures and functions of their actions.

While Ongka and the researchers may have talked at length, in the end he was only a useful resource person - an object- to which preconceived Western notions of empirical research were applied in order to separate him as an individual from the creative manifestations of himself and the behaviour associated with these manfiestations.

\section{Ownership of books and notebooks}

When the fieldwork season was over, the symmetrical relationships between the researchers and informants effectively came to an end. While the informants continued the ordinary aspects of their lives, the 
researchers went away with notebooks filled with observed primary data which would help them establish themselves in their own culture as members of the academic tribal community. The relationships they had left behind had been replaced instead by an expectation on the part of the informants about the nature of their future relationship.

Perhaps the greatest promise of the future-or obligation to return a gift-lies in the writing of books and articles. Obviously a book is of no immediate benefit to the studied community, unless the children of the informants learn to speak the language in which it is written. It is the writer who obtains ownership (through copyright) of the products of exchanged knowledge, because a text book is an object, like an archaeological artifact. Because these are tangible products, Ongka's claims of ownership are discredited. He may be the source, the originator of ideas-in much the same way as he credited the Europeans (or more specifically Strathern) as the source of European items - but he does not control the product as his property. Because his ideas are intangible he cannot prove ownership in a specific way.

The distinction between intangible ideas and the tangible products of their expression becomes less clear in the case of primary data. If Ongka does not have a stake in the books, what about the material contained in anthropological notebooks before it leaves an indigenous community? The notebooks are the property of the researcher and the primary data in itself is not valuable. The material is more a potential asset-like technology that transforms ideas into a visible form-and it is the creativity of the researcher that transforms it into a product that may or may not generate future returns. However, a book is also an indirect reflection of the relationship between the researchers and informants (and others). If the researchers are sponsored by academic institutions, those bodies may claim ownership of the product, or at least the researchers are obliged to make some return payments.

Marilyn Strathern says that, in order for a product to be of benefit, it has to meet contemporary demands. In most cases, books do not make money, and the ideas contained in such products have to travel along networks, the 'seeds of dispersed knowledge', so that they can grow in a number of sites. To establish a relationship between a producer and a product, the text-asproperty must be identified as originating from the native source. Once the product (text) is distanced from the source, the cultural knowledge comes to be identified with the writers of the text. Arguably, Marilyn Strathern's distinction between the products of collective life and products of useable 
knowledge parallels the separation between scholars and natives. In this regard, it is suggested that Ongka's claims of ownership rest upon the concept of control of cultural knowledge as products of collective liferecognisable objects (culture) and recognisable claims (identity). The validity of this proposal is supported by the preamble of the Constitution of Papua New Guinea, which says that we 'pay homage to the memory of our ancestors-the source of our strength and origin of our combined heritage' and 'acknowledge the worthy customs and traditional wisdoms of our people', and for Ongka it provides some basis for the claim of ownership of transmissibility of cultural knowledge over time.

\section{A bottle of kerosene}

Ongka did teach me one lesson. It is that we, the natives, have no way of evaluating outsiders and their involvement in our affairs, or what it means for our relationships with them (which take place within our own social setting) that they have associations, beliefs and social positions as members of another society (cf. Said 1991:10).

Until recently, those studied by anthropologists have accepted passively the right of outsiders to speak for them from an outside, a European, point of view. The cultures they created for us-for example, Melpa, Kuma and Chimbu - were manifestations of their own perceptions and personalities. For a period anthropological researchers enjoyed the hospitality of those they studied, but now people are increasingly aware of property ownership and no one can speak for Ongka, rather he spoke for himself to me in a plain language - the ownership of ideas and things.

However, one never can understand the politics of reciprocity; tomorrow Ongka may change his mind and say 'Andrew is a very nice person, because he helped me; and it is good that he wrote many books because other people know about us'. On one occasion Onkga coerced me to buy a bottle of kerosene for him, and he said 'now you know our ways better than them'. This is how intellectual property as an embodiment of exchanged ideas is embedded in social relations and should be appreciated among the community of intellectuals. If we are serious about intellectual property rights, we must have at least 700 indigenous anthropologists covering all the linguistic groupings in Papua New Guinea and producing their own materials; these groups may still cry out for the protection of their ideas from acts of intellectual theft. 


\section{Ownership of things}

\section{Exporting of knowledge}

Since the closure of the agricultural research station, the status of the Kuk historical site has been a cause for concern on the part of National Museum staff and archaeologists because of the takeover of the property by the original landowners and their subsequent use of the land. The threat of destruction has prompted appeals to larger organisations like the World Heritage Commission, for recognition of the site as one of importance to the history of humanity (Strathern and Stewart 1998). Jack Golson's concern about this issue brought him out of retirement to make several self-sponsored trips to Papua New Guinea (between 1994 and 1997).

The archaeological records at Kuk are situated within the boundaries of land owned by the Department of Agriculture and Livestock. For most of the period during which Kuk was intensively studied, this state ownership was assumed to provide a legitimate basis for the National Museum's custodianship of the cultural property. The closure of the Kuk station provided the foundation for the emergence of a third party interest-the original owners of Kuk. The politics of their new role is complicated by changing personal dynamics. The people with whom Jack Golson established relationships have gone into retirement from their positions of influence, and have been replaced by their children, and others, like $\mathrm{Ru}$, who participated in the excavations as a young man, have assumed positions of influence, wealth and prestige. They have a different view of their relationships with government and with researchers. It may be that some of them were instrumental in forcing the abandonment of the station and obstructing the use of buildings by the provincial authorities.

$\mathrm{Ru}$ is an important indigenous scholar who, like Ongka, featured in several films (Nairn, Strathern and Ongka 1983) and wrote an autobiography (also with the help of Andrew Strathern). Ru's comments set out at the beginning of this chapter were recorded three years after the first village meeting in November 1993. They were directed at Jack Golson, whose archaeological work on the prehistoric agricultural practices spanned a period of more than 20 years.

During the period of academic interest and study at Kuk, Ru associated with scholars operating within two quite different fields. Archaeological field methodology differs significantly from that of anthropology. It is primarily 
concerned with the remains of past societies, rather than tapping into the minds and thoughts of living people. As such, there need be little interaction between scholars and villagers about the production and maintenance of exchanged knowledge. In addition, this preoccupation with the past means that knowledge is gathered from observations of the physical landscape by researchers with different field expertise from that of anthropologists. Consequently, the product of useable knowledge comes to be identified closely with the scholars.

In contrast, anthropological researchers make repeated visits to the studied area and develop long term relations with the living communities. In the case of Kuk, they have effectively prevented any questioning about the ownership of knowledge by motivating the informants to write books about themselves. Practices of this kind were of little significance to the archaeologists who studied the site, since they were concerned with a period that went beyond the remembered history of the present occupants. Whereas Ru could discern some benefits from his social relationship with Andrew Strathern, he could see no similar benefit from his relationship with Golson. Ru may have felt that he gained recognition and status in anthropology but that he was left out in the production of archaeological knowledge. It was in this context that he made his remarks.

In what way could Jack Golson have left behind knowledge among the Kawelka? An anthropologist can contest Ongka's or Ru's comments by arguing that he or she gave something in exchange for the initial procurement of knowledge. A balance is maintained in which the informants and researchers both write books about themselves. Even if scholars had narrated the stories of the informants, the latter would still have gained the idea of a balance in the exchange of knowledge-equal participation in the production of a text. It does not matter if the scholars have written more books than the informants, since the ideals of reciprocity are based on balanced social relations rather than on exchanges of exact value.

The objects that are the archaeologist's 'informants'-like wooden digging sticks, pollen, sediments and structural features like ditches, fence posts and house sites-are mute. They do not talk in the way that Ongka and $\mathrm{Ru}$ did, but the archaeologists use rigorous scientific methods to make them speak for themselves. I suggested earlier that Ongka may have some rights to the notebooks of the anthropologist's field visits, since his community enabled their creation. When the informants die, taking with them the cultural knowledge recorded by the anthropologist, the notebooks may be-come the only record that exists of the cultural knowledge of earlier generations. 
The same cannot be said of archaeologists' field notes. Since the knowledge in them is gathered not from the minds of those long gone, but from the physical evidence they left behind, the archaeologist's notebooks are a simplified model or map to the knowledge; they are not the knowledge itself. The source of the knowledge is still buried in the swamps of Kuk. It is open to any Kawelka who may one day wish to follow the steps of Jack Golson and reproduce his or her own version of the human activities at Kuk swamp.

\section{Recovering old ground}

For a period after the closure of Kuk station, research work there abated. Following the meeting with the local landowners in late 1993, there were discussions about restarting archaeological fieldwork at the site. Meanwhile, human activity intensified in different parts of the abandoned station. However, most of the gardening activity was in the northeastern part, away from the southeastern blocks where most of the archaeological investigations had been carried out. An agreement was reached with the landowners that if there were plans to develop various plots within the station boundaries, the National Museum and the University of Papua New Guinea would be informed so as to allow for some salvage archaeological research.

What the researchers did not know until after the event was that the major clans of the Kawelka and Jika were moving across the boundaries of the old station in 1995 and 1996 and dividing the land among themselvesa process which might have been planned as early as 1990. The leaders of the Kawelka did not inform the researchers that this had taken place. It can be argued that, rather than hiding the truth, $\mathrm{Ru}$ took the view that it was none of the researchers' business. Although he concealed this information about the tribalisation of the state property, Ru kept his part of the deal. To him, four years was enough time for archaeologists to find money to do whatever they wanted. Since the blocks were the best land for garden activities and Ru's rivals staked claims by gardening in them, he may have been forced to make claims for himself. He thus took part in the rapid repossession of the property and its subdivision amongst selected family heads in 1996.

In November 1996, I visited Kuk with a Japanese television crew who were documenting aspects of early agriculture in Papua New Guinea. For the first time, I was able to inspect the southeastern part of the station where the main archaeological investigations had taken place in the 1970s. Since people had cleared the swamp vegetation to prepare gardens, I could see the 
traces of large prehistoric channels on the exposed surface; they were too deep to be affected by the shallow modern ditches, and were still waterlogged. The most disturbing observation was that the area of most archaeological interest, the area that ought to be protected, was under extensive cultivation, including some plots with coffee trees in various stages of maturity.

It was apparent that a clever strategy was being used to mask the gardening activities taking place on the repossessed land, and hence the encroachment on the locations of past archaeological investigations. By cultivating in areas which were invisible from nearby vantage points, the villagers had ensured that their activities would not be noticed. By the time I arrived at the end of 1996, most of the area previously subject to archaeological research was covered with food crops, vegetables, coffee trees and other trees like Casuarina. It appears that the Kawelka had been destroying the tangible evidence left by the previous owners (the state), and recreating a new domestic, personalised environment, in order to make a political statement about their ownership or reflect a legal claim to the control of the Kuk property. By destroying the tangible archaeological evidence that might provide a source that could stop them from owning the land (Muke 1998; Moutu 1978), the Kawelka placed the integrity of this internationally significant cultural heritage site at risk.

\section{The battlefield}

The Kuk station ground is like a traditional battlefield, where the imbalanced relations between two hostile groups are contested. In battle, the objective is not the permanent acquisition of the land of a defeated group, but the total destruction of the tangible evidence of their opponent's cultural activity within the territory. The idea is to turn the cultivated cultural landscape into a wild, barren no-man's territory. Upon the return to their own territory, the defeated group's initial settlements and gardening activities are concentrated on portions of territory away from the battle frontier. Slowly the settlements progress towards the battlefields, which are also closest to the striking positions of the opponents in the event of war. As soon as the bulk of the territory is cultivated, the group asserts its sociopolitical autonomy as a territorial unit. The lost ground is now legally theirs.

In their campaign to regain Kuk, Ru's group adopted a similar strategy. The state is the enemy whom they accuse of stealing their land through very 
cheap deals with their fathers and grandfathers. The hostilities of the early 1990 s, involving both a war of words and physical confrontations with government personnel, was a deliberate attempt to recolonise the property from the private ownership (of the state) to communal ownership (by the group). To prove that it is legally theirs, the Kawelka have to refer to the presence of their own culturally created tangible evidence on the landscape. How can they claim that the property is their own when the tangible evidence shows the hallmarks of the state's legitimate claim of property ownership?

The obvious strategy is to destroy most of the tangible records on the ground and then create new evidence which is aligned more towards the Kawelka's conceptions of a cultural landscape. This is partly what has been happening at Kuk over the last decade. The locals have systematically destroyed the tangible evidence left by the state. First they felled gum trees, occupied residential houses and offices and allowed pigs into the station, who bulldozed the land on top of the major drain networks. The next set of activities involved the establishment of initial gardens in the boundary zones between the state and customary lands, the division of the major blocks among the main sub-clans, the assertion of individual claims to plots within the main blocks, the replacement of food crops with cash crops (mainly coffee trees) and the construction of new houses.

At no stage of the domestication process initiated by the villagers did the state authorities counter-attack (for example, by sending in police to arrest and punish the trouble makers). When wokabaut sawmills were used to fell the gum trees, there was no intervention by Division of Agriculture and Livestock officers at the provincial level. The Division of Agriculture and Livestock's failure to move back into Kuk allowed the people to proceed to the final stages of legitimating their tribal ownership by the symbolic act of planting coffee trees, not only as economically significant but as permanent markers. They are tangible evidence which serve as a bargaining point for a large compensation demand from the people in the event of a claim of ownership by the state. The question now is, who owns the archaeological sites?

\section{Ownership of the Kuk site}

Ru's comments referred to money in terms of the fruits of his labour. He saw the fruits of that labour as the save (knowledge) that Golson wrote in his notebooks (without Ru's help) and took to Australia. He reproduced it 
there, and therefore its indirect benefits were enjoyed by others. Ru argues that, since Golson did not leave the knowledge behind, what remains in the soil should at least provide some benefit for the future generations of the community now there is a pressing need for land. Unless someone finds new land for the Kawelka, the Kuk property is theirs to keep.

Ironically, the tangible records from which the product of useable knowledge were created are still in the Kuk swamp. They have been buried there for many thousands of years, and the Kawellka are only the contemporary owners in a succession of previous owners of the Kuk swamp. In other words, Jack Golson only constructed his knowledge from that part of save that will always remain the property of the people. It can be argued (as is prescribed in the Australian Archaeological Association Code of Ethics) that 'the indigenous cultural heritage rightfully belongs to the indigenous descendants of that heritage except items given as personal gifts to non-indigenous people or given or sold to non-indigenous institutions' (Principle 5). If we apply this principle to the Kuk site, it is obvious that it remains the property of the traditional landowners. The ancestors left the traces behind, and present generations are the custodians of the places, tools and other resources used by their ancestors, as part of a single social continuum. From this perspective, the decision to protect, conserve and promote that aspect of the eroding culture must be in the hands of the indigenous people themselves.

Perhaps $\mathrm{Ru}$ is aware of this-it may not be a total coincidence that his plots are in the area that has received intensive archaeological attention. He has indicated that scientists may use his land free of charge, but will have to negotiate the rest with other landowners. The problem for archaeologists is that there are more than 50 owners of plots within the several blocks which are of interest to archaeology. A researcher would need to get permission from several individuals to do any kind of investigations. There are real questions now about how to protect the source of primary data for future returns, when it is in the ownership of so many individuals. It is cultural property which can bring direct and indirect benefits to the community. Unfortunately, the custodianship or ownership of cultural resource materials has become confused with the economic value of the swamps themselves, and the cash crops which can be grown within them. Only a significant effort at public education will change the attitude of the people on that issue. 


\section{Other cases}

As the idea of making money from land becomes more and more entrenched, the idea of selling objects of history from the surface of the ground becomes increasingly attractive. The emerging economic significance attached to items of cultural value raises issues about the loss of this cultural heritage. Kuk is only the most prominent of several cases of conflict between economic interest and cultural heritage that have arisen in the Wahgi region alone over recent years. These have involved the sale of objects of cultural significance, like stone axes and wooden spades discovered during drainage, and also claims for compensation to be paid before investigations could be made at the sites of such discoveries.

Particularly instructive is the case of Kana near Minj. I chose this area for my own investigations, because I thought that my personal connections might enable me to avoid the difficulties arising from the demands for money which had been encountered in other places. Several sites were located, and archaeological investigations were carried out at two of them. In 1993 and $1994 \mathrm{I} \mathrm{had} \mathrm{no} \mathrm{problems} \mathrm{gaining} \mathrm{access} \mathrm{to} \mathrm{the} \mathrm{Kana} \mathrm{site} \mathrm{(Muke}$ n.d.), partly because of a very good relationship with the plantation manager and partly because the coffee plantation was still seen as company property. However, by 1995 the loan was fully repaid and there was internal conflict among the local landowner groups. The company was dissolved and the coffee plantation was divided among the people themselves. The areas of specific archaeological interest have been divided among three families. While one family approved of the archaeological work in the area, the other demanded payments. Since 1995 I have been forced to make small financial contributions to the coffee owners in order to have access to this important site. Should this practice be discouraged or encouraged? This is a question to which I cannot provide any immediate answer.

\section{Conclusion}

Swamplands like those of the Wahgi Valley are a non-renewable resource, an ecological museum and an extraordinarily important relic in the cultural landscape library for scientific study. Because they are permanently waterlogged and too deep to be affected by the fluctuating water table, the swamps contain layers of humic organic deposits which are effectively sealed in a wet and airless environment. This favours their preservation, as long as the waterlogging is more or less permanent up to 
the time of exposure (Renfrew and Bahn 1991). The different phases of past swamp cultivation are registered at different levels of deposits by the superimposition of one layer of sediment on the other when the ditches of an earlier period of drained agriculture were filled in and covered over by sediment during a following period of abandonment (Golson 1982).

The challenge to preserve Kuk as a heritage site is contested by the traditional landowners. One has to seriously think about Ru's comments

It is hard for me to try and stop them from destroying the prehistoric sites. You know when they have already made their gardens, they will ask you for money if you want to excavate on their land.

Archaeologists are in an even more difficult position in trying to stop destruction at the national level. If $\mathrm{Ru}$ as a local leader cannot change the opinion of the owners, who can? The potential for selling archaeological heritage items or paying for access to the sites or sources of knowledge is becoming an enterprise activity in itself.

Coffee production is a high export income earner and Highlanders often refer to it as a pot of gold. They equate coffee with mineral resources. Compensation is awarded to landowners with mineral deposits, and people are aware that multinational companies pay for trees, bushes and anything of significance destroyed. Why should it not be the same for archaeological research in the swamplands? Such underlying rationality has influenced people to salvage genuine archaeological objects and sell them for cash, and they have demanded that archaeologists pay them first before they investigate the appearance of past cultural activities in these former swamps.

At present, it is only through goodwill and appreciation by the people themselves of the importance of cultural heritage that sites on the landscape are left undisturbed. Kuk is a valuable case study, and illustrates the wider problems of destruction of heritage. There are a number of ways to address these problems. They include introducing acts and policies on cultural property and heritage management, recommending World Heritage listing and conducting scientific investigations which would add a final chapter to Golson's version of the agricultural history of the Highlands. Unless efforts like these are made, the existence of Kuk (and sites of similar antiquity) will only be remembered on paper. 


\section{Notes}

1 This is not a direct quote. Rather, I have extracted and simplified the essential elements of this conversation.

2 Translated from the original Tok Pisin: Jack Golson i kam na mipela wok wantaim long baret. Em i baim mipela pinis. Tasol Jack $i$ kisim save i go long Australia. Em i no lusim wantaim mipela. Ol samting bilong tumbuna yu laik mipela lukautim, em tru samting bilong bihain. Nau ol Kawelka sot long graun na ol kisim block pinis. Em i hat tru long mi stopim ol long noken bakarapim ol baret bilong tumbuna. Yu save taim ol plantim kaikai pinis ol bai askim yu long baim ol sapos yu laik wok long graun bilong ol.

3 BP (before present) refers to a present which is fixed at 1950 in terms of radiocarbon dates. 